\title{
Ecological Features of the Exotic Wasp Vespula Vulgaris L. 1758 (Hymenoptera: Vespidae) Invading the Southernmost Unesco Biosphere Reserve
}

Javier Rendoll-Cárcamo ( $\sim$ javier.rendoll@gmail.com )

Universidad de Magallanes https://orcid.org/0000-0003-1928-0914

\section{Peter Convey}

BAS: British Antarctic Survey

\section{Melisa Gañán}

Universidad de Magallanes

Alan Maldonado-Márquez

Universidad de Magallanes

Luna Menares Zuñiga

Pontificia Universidad Catolica de Chile

\section{Tamara Contador}

Universidad de Magallanes

\section{Research Article}

Keywords: Biosphere Reserve, non-native, invasive species, sub-Antarctic, Vespula vulgaris

Posted Date: October 18th, 2021

DOl: https://doi.org/10.21203/rs.3.rs-820104/v1

License: (9) (i) This work is licensed under a Creative Commons Attribution 4.0 International License. Read Full License 


\section{Abstract}

Invasive alien species may cause substantial changes and damaging impacts in the ecosystems they invade. Here, we document the current distribution and ecological interactions with native biota of the relatively recently introduced wasp, Vespula vulgaris, in the southern part of the Cape Horn Biosphere Reserve. We conducted surveys and field studies in four different habitats on Navarino Island: evergreen, deciduous and mixed forests, and shrublands. The spread of $V$. vulgaris through the island since its first detection has led to it occupying suitable habitats for nesting and foraging, both in urban and rural settings. The presence of $V$. vulgaris on islands and remote areas of the CHBR is likely the result of marine human movement through the channels withing the reserve. Wasp foraging composition was different on each of the four studied habitats, yet strongly linked to each habitat's resources, indicating the inherent ability of $V$. vulgaris of exploiting surrounding resources efficiently. The lack of natural competitors and availability of multiple resources as allowed $V$. vulgaris to rapidly become a common pest in urban and rural settings in the southern extreme of South America. In this context, we believe that eradication would be impossible, although it would be possible to control populations at localized scales with proper planning and long-term management. Our results can act as a base for management planning, and we strongly recommend social engagement and dialog with pertinent governmental institutions to achieve this challenging task.

\section{Introduction}

For hundreds of years, humans have been responsible for introducing plants, animals, and other organisms into new regions, slowly homogenizing the world's biota (Hulme 2009, Pysek et al. 2020). In recent decades, in concert with the globalization of human activities, the pace of this process has accelerated rapidly, facilitated through commerce, transport, tourism, and global environmental change (Blackburn et al. 2011). These activities enable the accidental or intentional introduction of non-native species in new environments, with examples being present in almost all ecosystems today (Pysek et al. 2020). It is estimated that around $5 \%$ of introduced non-native species will establish and have a significant impact on the receiving community, with social insects (ants, wasps, bees, and termites) accounting for a quarter of these species (Beggs et al. 2011). Global and regional 'horizon scanning' assessments have regularly highlighted the potential threats posed by these groups (Garnas et al. 2016, Roy et al. 2014). The success of social insect introductions is likely due to a combination of associations with human goods, multiple introduction events, and a low probability of detection by standard biosecurity protocols (Brenton-Rule et al. 2018).

Wasps of the genus Vespula (Vespidae) have been introduced and become established in several countries in the Southern Hemisphere (Lester and Beggs 2019). Social vespids have high rates of reproduction and dispersal capabilities, as well as exploit resources (habitat and food) more efficiently than other insects (Moller 1996). The use of visual, auditory, and olfactory cues in resource exploitation by these wasps has led to novel biotic interactions in the newly occupied regions, such as removing competing ants during foraging (Grangier and Lester 2011) or primary nectar robbing (Rendoll-Cárcamo 
et al. 2017a). Vespula wasps can live in high densities in both urban and rural areas, and their effects on natural and agricultural environments, as well as urban areas, are generally negative and well documented. (Sackmann and Corley 2007, Gardner-Gee and Beggs 2013). Furthermore, they can represent a nuisance to human society and a threat to health (Rust and Su 2012). Vespula wasps, also known as "yellow jackets," are eusocial insects native to the Holarctic region that have become successful invaders in regions as distant as Australia, New Zealand, and South America. They are notoriously difficult to manage and control. (Moller 1996, Beggs et al. 1998). In South America (Argentina and Chile), as elsewhere, the introduction and expansion of Vespula species is likely to be an inadvertent result of human movement of goods and transport of mated queens (Beggs et al. 2011).

The first record of a yellow jacket in central Chile was documented in the 1970s (initially recorded as $V$. maculinfrons, later confirmed as $V$. germanica) (Peña et al. 1975), with the species reaching the south of the country only 25 years later (Pérez 2000). Barrera-Medina and Vidal (2013) recorded the presence of $V$. vulgaris in central Chile in 2013, while Masciocchi et al. (2010) documented the species in Argentina. The recent dates of the first reports of $V$. vulgaris in Chile and Argentina may suggest that the species had previously gone un-noticed due to its general morphological and behavioral similarities with $V$. germanica (Masciocchi et al. 2010, Barrera-Medina and Vidal 2013). The first and currently southernmost published records of Vespula wasps were provided by Sola et al. (2015) in and near Puerto Williams on Navarino Island (southern Magellanic region, Chile) during 2012 and 2014. Later, the species identity was confirmed as V. vulgaris (Rendoll-Cárcamo et al. 2016). Despite being found in 2016, V. germanica has not been formally reported in peri-urban settings on Navarino Island.

The UNESCO Cape Horn Biosphere Reserve (CHBR) is located in southern Chile and is the southernmost biosphere reserve declared worldwide (Rozzi et al. 2020). The CHBR is located within the Magellanic Forests sub-Antarctic ecoregion, which is largely undeveloped and is recognized as one of the world's 24 last wilderness areas due to its high proportion of native vegetation and low urban and industrial development. (Mittermeier et al. 2003, Rozzi et al. 2020). Three Chilean National Parks are located within the CHBR (Cape Horn, Alberto de Agostini, and Yendegaia), each with a core, transition, and buffer zone. (Rozzi et al. 2020). However, the CHBR is not completely immune from anthropogenic influence and is vulnerable to introduced species with invasive potential. Anderson et al. (2006) also highlighted the presence of non-native vertebrates (beavers, rodents, mink, dogs, salmonids) and the potential impacts on native wildlife. Nonetheless, non-native plants and invertebrates have received minimal attention (Creté et al. 2020, Rendoll-Cárcamo et al. 2017a, b). Based on the results of a systematic monitoring program established from 2015 to 2021, this study provides an update on the current distribution of $V$. vulgaris and $V$. germanica in the CHBR, with a primary focus on Navarino Island. In addition, we document $V$. vulgaris foraging composition, nest activity, and associations with native flora and fauna in the various habitats where this species has been found. The annual dynamics of $V$. vulgaris life cycle on Navarino Island are described.

\section{Materials And Methods}




\section{Area and study sites}

Navarino Island is located south of Tierra del Fuego and the Beagle Channel within the CHBR (Fig. 1). Nothofagus forests, coastal shrublands, wetlands, peat bogs, and high-Andean tundra are among the island's native ecosystems (Pisano 1977). The island remains largely undeveloped today, with a single vehicular road running through the length of the island's north coast, from west to east, covering 81 kilometers. This road served as a transect for determining wasp distributions. We also visited Yendegaia National Park during April 2017, where three locations were surveyed on foot, not finding nests but identifying wasp individuals. Hoste Island, specifically the location Kanasaca, was visited by personnel of the Agricultural and Livestock Service of Puerto Williams during February 2019.

\section{Compilation of distribution records}

Between 2015 and 2021, we conducted systematic waspcensuses and collections along the north coast of Navarino Island during the austral summer (late December to mid-March). We recorded each sighting, capture or nest detection in a corridor of $15 \mathrm{~m}$ to each side of the road (wherever accessible). We recorded the habitat type, vegetation and any ecological interaction observed with native biota. Additionally, throughout the months of February 2016, 2017, and 2018, we registered opportunistic sightings, catches, and nest records in Puerto Toro, an isolated settlement on Navarino Island's east coast. During April 2017, we sampled in Yendegaia National Park and during the summers of 2019, 2020 and 2021 in four different watersheds on Navarino Island (Fig. 1). The only record from Kanasaca (Hoste Island) was documented in 2019 by personnel of the Agricultural and Livestock Service of Puerto Williams. We georeferenced each location examined with a GPSmap 78sc Garmin@ unit.

\section{Foraging associations}

During February 2018, we sampled foraging items taken by $V$. vulgaris to their nest $(\mathrm{n}=32$ nests) along the north shore of Navarino Island. We identified four main habitat types in which $V$. vulgaris constructs nests: shrublands, deciduous forests, evergreen forests, and mixed forests. To date, no nests of $V$. germanica have been located. With an aerial net placed $20-50 \mathrm{~cm}$ from the nest entrance, we captured foraging workers returning to nests ( $n=30$ individuals per nest). Due to the stress of capture, workers frequently released foraged objects into the net, which we gathered with fine-tipped forceps; if objects were not released, we kept both the wasp and the foraged object in a $50 \mathrm{~mL}$ ethanol container. To avoid discoloration, we stored wasps and released items in individual vials of $60 \%$ ethanol and then transported them to the Wankara Laboratory in Puerto Williams, where they were identified using a stereo microscope (Leica S6D). We identified prey items to order or family level when possible and later classified items as follows: prey type = complete animal or fragments, fruit type = complete or fragments of berries, liquids = colored or colorless fluids, wood pulp = wood fragments or woody agglutination, and non-apparent load when wasps returned without items. This proved to be a simple and effective alternative to Harris's (1991) suggestions, aided by the wasps' lack of aggression. We captured returning wasps around noon when they were most active (Malham et al. 1991) and made additional observations of their interactions with native biota on an opportunistic basis. 
We counted the number of wasps that entered each nest ( $n=32$, eight in each habitat) to compare nest activity across habitats. In this context, we recorded the mean number of individuals entering the nest ( $\mathrm{n}$ $=5$ counts $)$ and those leaving the nest $(n=5$ counts) over a 60-second period, with each count separated by identical-length non-counting intervals (Harris 1991, Kasper et al. 2008). We assessed activity near midday, as Malham et al. (1991) had done, and during the same week (Kasper et al. 2008). The traffic rate provides a useful estimate of worker abundance for management planning purposes (Malham et al. 1991).

\section{Data analyses}

To analyze differences of foraged item composition between habitats, we conducted a Permutation Analysis of Variance (PERMANOVA), using PRIMER-E v7 with Permanova+ add-on package (Clarke and Gorley 2015). Prior to PERMANOVA, a PERMDISP test was performed to evaluate data homogeneity within and between groups (Anderson, 2005). For the composition analysis, data were square root transformed and Bray-Curtis dissimilarity matrices were calculated between pairs of observations. To visualize foraging item composition between habitats a CAP analysis (Canonical Analysis of Principal Coordinates) was performed. Nest activity differences between habitats were assessed by performing a Kruskal-Wallis analysis and post hoc Wilcoxon comparisons. The significance level was set at $\mathrm{a}=0.05$. Kruskal-Wallis analyses were performed in Statistica 7, PERMANOVA, CAP and SIMPER were performed in Primer 7.0 (PRIMER-E, Ltd. Plymouth, UK).

\section{Results}

\section{Vespula wasp distribution}

The first non-native wasps collected on Navarino Island in 2015 were identified as $V$. vulgaris, with all records being in the urban environment of Puerto Williams. During 2016, the presence of $V$. vulgaris was documented far from the main town ( $30 \mathrm{~km}$ to the east and $10 \mathrm{~km}$ to the west), although nests were found predominantly in peri-urban settings with evident anthropogenic activity impact (non-authorized waste collection sites and forestry management depots) and inhabited rural settings (farms, greenhouses). Much wider distribution expansion in the natural environment remote from human settlements became apparent in 2017, during which $V$. vulgaris was recorded along virtually the entire north coast of Navarino Island, approximately $90 \mathrm{~km}$ in length (Fig. 2). In the same year, the species was recorded in the isolated Puerto Toro (a village on the east coast of Navarino Island), and in Yendegaia National Park (Fig. 2). In the summers of 2018 and 2019, V. vulgaris was present throughout the north coast of the island, in Puerto Toro and had reached the southwest of the island (Wulaia), as well as being documented for the first time in Hoste Island. In addition to being present in almost all terrestrial ecosystems, a $V$. vulgaris nest was recorded at $450 \mathrm{~m}$ a.s.I., close to the tree line on Navarino Island. During the summers of 2020 and 2021, V. vulgaris was found off the forest margin of Windhond lake in 
the southern part of the island, south of the Dientes de Navarino mountain range, and towards the southeast. In addition, $V$. vulgaris workers were found foraging in different habitats through valleys (forests, shrublands and peatlands), from low elevations up to the tree line (500-600 m a.s.l.). Nests were recorded along hiking trails, in dead and living trees, old growth and secondary forests, peat bog margins and in riparian habitats close to streams and lagoons.

The first specimens of $V$. germanica were recorded and collected in 2016 at four different locations within Navarino Island (queens $n=2$, workers $n=10$, Fig. 3). During 2017, workers $(n=15)$ and a single drone were collected at the same locations. During 2018 and 2019, V. germanica workers were recorded at 12 locations, the majority of these being new (Fig. 3). During 2020 and 2021, no records of $V$. germanica were noted. All records to date have been along the north coast of Navarino Island, and no nests have yet been located.

\section{Foraging associations}

Vespula wasps have a broad association with the biotic components of the habitats they nest in, and workers are commonly seen exploiting resources for food and nest maintenance (Table 1). Significant differences in foraged item composition were found between all habitats (PERMANOVA, $F=10.188 p=$ 0.001 , Table 2, Fig. 5). The most frequent prey items were dipterans (mainly Tipulidae and Syrphidae), particularly in deciduous, evergreen, and mixed forests (Fig. 6). Occasional prey such as beetles, moths, spiders and dragonflies were less frequently observed in the surveyed nests and related to their presence in a particular habitat (Table 1, Fig. 6). The main non-insect source foraged by workers were berries, mainly Berberis microphylla, which are common through the island. Other berries (Rubus geoides and Ribes magellanicum) were foraged in the specific habitats in which they grow (Fig. 6). Items that are related to nest maintenance (liquids and pulp) were common and regularly foraged in all habitats (Fig. 6). Regarding the associations of $V$. vulgaris with native and non-native biota of the CHBR, 16 plant associations were found, of which only three species were non-native (Table 2). The type of interaction was mainly foraging berries in shrubs of the genera Berberis, Empetrum, Ribes and Rubus. Wasps have also been found robbing nectar, eating petals from flowers, preying on arthropods associated with trees and shrubs and chewing branches for wood pulp. Regarding the interactions with fauna, we found an association with nine different native invertebrate species, mostly involving predation.

\section{Nest activity}

Activity was broadly comparable across all four habitat types, although significant differences were detected (Kruskal-Wallis $\mathrm{H}=22.9924 ; p<0.001$, Table 3 ). The mean nest activity measured in evergreen forests was significantly lower compared to shrublands and mixed forests (Fig. 4). Recorded nest activity in deciduous forests was highly variable (see Table 3, Fig. 4) and significantly different from the activity in shrublands and mixed forests but not that in evergreen forests. 
Table 1. Vespula wasp associations with native and non-native biota in the Cape Horn Biosphere Reserve, southern Chile. 
Species/ Flora/ fauna Origin Nature of interaction

organisms

\begin{tabular}{|c|c|c|c|}
\hline $\begin{array}{l}\text { Baccharis } \\
\text { patagonica }\end{array}$ & Shrub & Native & Hunting for arthropods \\
\hline $\begin{array}{l}\text { Berberis } \\
\text { microphylla }\end{array}$ & Shrub & Native & Foraging berries \\
\hline Berberis ilicifolia & Shrub & Native & Foraging berries \\
\hline $\begin{array}{l}\text { Chiliotrichum } \\
\text { diffusum }\end{array}$ & Shrub & Native & Hunting for arthropods \\
\hline Drimys winteri & Tree & Native & Eating petals from flowers \\
\hline $\begin{array}{l}\text { Embothrium } \\
\text { coccineum }\end{array}$ & Tree & Native & Nectar robbing \\
\hline Empetrum rubrum & Shrub & Native & Foraging berries \\
\hline $\begin{array}{l}\text { Gaultheria } \\
\text { mucronata }\end{array}$ & Shrub & Native & Foraging berries \\
\hline $\begin{array}{l}\text { Nothofagus } \\
\text { antarctica }\end{array}$ & Tree & Native & $\begin{array}{l}\text { Hunting for arthropods and chewing branches for } \\
\text { wood pulp }\end{array}$ \\
\hline $\begin{array}{l}\text { Nothofagus } \\
\text { betuloides }\end{array}$ & Tree & Native & $\begin{array}{l}\text { Hunting for arthropods and chewing branches for } \\
\text { wood pulp }\end{array}$ \\
\hline $\begin{array}{l}\text { Nothofagus } \\
\text { pumilio }\end{array}$ & Tree & Native & $\begin{array}{l}\text { Hunting for arthropods and chewing branches for } \\
\text { wood pulp }\end{array}$ \\
\hline $\begin{array}{l}\text { Ribes } \\
\text { magellanicum }\end{array}$ & Shrub & Native & Foraging berries \\
\hline Ribes uva-crispa & Shrub & $\begin{array}{l}\text { Non- } \\
\text { native }\end{array}$ & Foraging berries \\
\hline Rubus geoides & Herb & Native & Foraging berries \\
\hline Rubus idaeus & Herb & $\begin{array}{l}\text { Non- } \\
\text { native }\end{array}$ & Foraging berries \\
\hline $\begin{array}{l}\text { Taraxacum } \\
\text { officinale }\end{array}$ & Dandelion & $\begin{array}{l}\text { Non- } \\
\text { native }\end{array}$ & Eating petals from flowers \\
\hline Aegorhinus vitulus & Weevil & Native & Predation \\
\hline Ericchius femoralis & Stag beetle & Native & $\begin{array}{l}\text { Opportunistic robbery of tree sap while beetles } \\
\text { feed }\end{array}$ \\
\hline $\begin{array}{l}\text { Rhionaeschna } \\
\text { variegata }\end{array}$ & Dragonfly & Native & Defence when approaches nests \\
\hline Anyphaenidae & Spiders & Native & Predation \\
\hline Araneidae & Spiders & Native & Predation \\
\hline
\end{tabular}




\begin{tabular}{llll} 
Geometridae & $\begin{array}{l}\text { Geometer } \\
\text { moths }\end{array}$ & Native & Predation on larvae \\
\hline Lycosidae & Spiders & Native & Predation \\
\hline Syrphidae & Hover flies & Native & Predation \\
\hline Tipulidae & Crane flies & Native & Predation
\end{tabular}

Table 2. PERMANOVA analysis and post hoc pairwise comparisons of Vespula vulgaris foraged item composition in different habitats on Navarino Island, Cape Horn Biosphere Reserve, southern Chile.

\begin{tabular}{lcccll} 
Source & $\mathrm{df}$ & $\mathrm{SS}$ & $\mathrm{MS}$ & $\mathrm{F}$ & $p$ \\
\hline Habitat & 3 & 5599.7 & 1866.6 & 10.188 & $\mathbf{0 . 0 0 1}$ \\
\hline Res & 28 & 5130.1 & 183.22 & & \\
\hline Habitat & & & $\mathrm{t}$ & $p$ & \\
\hline Deciduous forest - Evergreen forest & 3.4228 & $\mathbf{0 . 0 0 1}$ & \\
\hline Deciduous forest - Mixed forest & 2.7385 & $\mathbf{0 . 0 0 2}$ & \\
\hline Deciduous forest - Shrubland & 3.1166 & $\mathbf{0 . 0 0 1}$ & \\
\hline Evergreen forest - Mixed forest & 3.148 & $\mathbf{0 . 0 0 1}$ & \\
\hline Evergreen forest - Shrubland & 4.5562 & $\mathbf{0 . 0 0 1}$ & \\
\hline Mixed forest - Shrubland & 2.4664 & $\mathbf{0 . 0 0 1}$ &
\end{tabular}

Table 3. Mean ( $\pm S E)$, maximum and minimum, Kruskal-Wallis non-parametric analyses and Wilcoxon post hoc comparisons of wasp nest activity (numbers entering and leaving the nest) measured in February 2018 at the entrances of Vespula vulgaris nests in different habitat types on Navarino Island, Cape Horn Biosphere Reserve, southern Chile. 


\begin{tabular}{lllll} 
Habitat type & Deciduous forest & Evergreen forest & Mixed forest & Shrubland \\
\hline Mean \pm SE & $46.28( \pm 6.77)$ & $36.45( \pm 2.60)$ & $51.95( \pm 2.85)$ & $50.5( \pm 1.78)$ \\
\hline Max & 155 & 69 & 76 & 69 \\
\hline Min & 7 & 14 & 21 & 32 \\
\hline Kruskal-Wallis & H & $p$ & & \\
\hline & 22.9924 & $<0.001$ & & \\
\hline Wilcoxon comparisons & & & & \\
\hline Deciduous forest & & & & \\
\hline Evergreen forest & 1 & & &
\end{tabular}

\section{Discussion}

Vespula wasps are now widespread from central Chile and Argentina all the way to the southern tip of South America, including in the Magellanic Sub-Antarctic ecoregion and the Cape Horn Biosphere Reserve (CHBR). Expanding distributions reported for wasp species (Sorvari 2013) and other insects (Parmesan et al. 1999) have been suggested as direct or indirect consequences of ongoing global environmental change, although in this instance this is hard to separate from distribution expansion from original introduction locations. The spread of $V$. vulgaris and $V$. germanica in the region considered here has likely been facilitated by a combination of human movement (Masciocchi et al. 2013), the species' suite of traits (Moller 1996, Beggs et al. 2011) and local resource availability. Our data documents rapid colonization of multiple habitats on Navarino Island, located at the southern margin of the CHBR, starting with the entry points to the island, Puerto Williams and Puerto Navarino, and later expanding along the entire north coast, later towards the southeast, southwest and currently reaching almost to the southern margins of the island. A combination of factors such as lack of enemy regulation, less efficient competitors, landscape characteristics (availability of rivers and water supplies), greater availability and quality of resources or less adverse environmental conditions could enhance niche occupation opportunities (MacLeod et al. 2009, Bertolino et al. 2016, Lester et al. 2017). Any impact of adverse climatic conditions, as might be expected in the Magellanic Sub-Antarctic region (Rosenfeld et al. 2020), could be mitigated by the availability of urban and rural human settlements with suitable synanthropic habitats in the early stages of the introduction and establishment process (Kasper et al. 2008, Rust and Su 2012). In sub-Arctic Alaska, the thermal tolerance of $V$. vulgaris has been studied by Barnes et al. (1996), finding that it can supercool to below $-10^{\circ} \mathrm{C}$. These wasps, while freeze intolerant, can avoid freezing and survive by supercooling and hibernating in litter or finding refuge in human facilities (Barnes et al. 1996, Lester and Beggs 2019). This physiological capacity to survive winter conditions in the sub- 
Arctic ecoregion, which experiences colder temperatures than those characterizing the sub-Antarctic regions (Convey 1996, Danks, 1996), is likely to be an important factor facilitating the species' spread.

Observed differences in foraged item composition between habitats (deciduous forest, evergreen forest, mixed forest and shrubland) in our study are likely linked to the availability and quality of food sources in each habitat (Beggs 2001). Vespula wasps are known for high carbohydrate intake (Harris 1991), which in the study regions is mainly foraged from native berries such as the Magellan barberry (Berberis microphylla) and rainberry (Rubus geoides), and nectar robbing from the Chilean firebush (Embothrium coccineum) during its flowering period (Rendoll-Cárcamo et al. 2017a). Our data also highlight the opportunistic nature of the diet of Vespula wasps in newly invaded habitats (Richter 2000). Our findings are consistent with numerous previous studies of the consequences of introductions of these wasps (e.g. Richter 2000, Lester and Beggs 2019). Density-dependent predation effects of higher wasp abundances can have considerable impacts on invertebrates (Grangier and Lester 2011), particularly on lepidopteran larvae, dipterans and spiders (Beggs and Rees 1999, Toft and Rees 1998). Furthermore, high densities of wasps may pressure and disrupt pollination networks by preying on pollinators or competing for resources (Rendoll-Cárcamo et al. 2017a), where $V$. vulgaris acts as a nectar primary robber by making holes with its jaws at the base of the corollas of Embothrium coccineum flowers. In the absence of native predators, alien Vespula wasps pose a severe threat to regional endemics and specialist species, and such aggressive predators can have disproportionately large impacts (Lebouvier et al. 2020). However, quantification of the effects of $V$. vulgaris on native arthropods and ecological networks has yet to be attempted.

The life cycle of Vespula wasps comprises the emergence of fertilized queens in late spring that establish new nests. During the warmer season, workers support colony development by foraging and expanding the nests. Near the end of summer, the production of queens and drones takes place, and then queens mate and leave the nest to find hibernation sites (Fig. 5). According to this cycle, wasp colony dynamics in southern Chile are similar to those characterizing their native range (Lester et al. 2017).. Nonetheless, we have detected exceptionally early emergence of queens and successful development of nests, leading to longer active seasons (JRC, obs. pers.). Lester et al. (2017) suggested that extended wasp active seasons, as noted in New Zealand, may be the result of higher food quality and abundance, and a lack of predators and competitors, giving enhanced niche opportunities (Beggs et al. 2011).

These characteristics would ensure the success of the establishment and dispersal observed in $V$. vulgaris, consistent with hypotheses that address the effect of biotic variables such as island susceptibility and biotic resistance (Pereira et al. 2016).

The effects of invasive wasps may be exacerbated by the presence of another invasive hymenopteran recorded in the CHBR, Bombus terrestris (Rendoll-Cárcamo et al. 2017b). Synergistic interactions between invasive hymenopterans could disrupt native pollination networks and further ecosystem functioning (Vanbergen et al. 2018). The management of Vespula wasp invasions is challenging, further emphasizing the importance of prevention of such invasions (Hughes and Convey 2012), whose impacts 
may rapidly become practically irreversible, especially in a largely inaccessible and uninhabited region such as the CHBR. In the context of management options available on Navarino island, the next steps are to identify urban and rural inhabited areas suitable for control actions aiming to minimize wasp presence, impacts and ability to rely on domestic crops, greenhouses, recreational spaces, tourism activities and human health. We recognize that eradication would be impossible yet control at local spatial scales can be achieved if well planned and executed (Beggs et al. 2011). The results presented here can act as a base for management planning and, as suggested by Rendoll-Cárcamo et al. (2017a), we strongly recommend social engagement and dialog with pertinent governmental institutions in order to achieve this challenging task.

\section{Declarations}

Funding. No funding was received for conducting this study.

Conflicts of interest/Competing interests. The authors have no conflicts of interest to declare that are relevant to the content of this article.

Availability of data and material. The datasets generated during and/or analyzed during the current study are available from the corresponding author on reasonable request.

Code availability. Not applicable

Authors' contributions. Javier Rendoll-Cárcamo conceived the idea and design the study. Field work and data collection was performed by Javier Rendoll-Cárcamo, Alan Maldonado-Márquez and Luna Menares Zuñiga. Data preparation and analyses were performed by Javier Rendoll-Cárcamo, Peter Convey, Melisa Gañán and Tamara Contador. The first draft of the manuscript was written by Javier Rendoll-Cárcamo and Peter Convey, and all authors commented on previous versions of the manuscript. All authors read and approved the final manuscript.

\section{ACKNOWLEDGEMENTS}

JRC is supported by the National Agency for Research and Development (ANID)/ Scholarship Program/ DOCTORADO BECAS CHILE/2021 - 21212048, and PC by NERC core funding to the BAS' Biodiversity, Evolution and Adaptation' Team. We also thank Cristian Soto, Fernando Cárdenas, Lorena Saavedra, Javiera Pineda and Lukas Quinteros, for their help during fieldwork. This study is part of the initiative "Niche modelling, invasion stage and habitat preferences of alien Vespula wasps (Hymenoptera: Vespidae) in Navarino island ( $\left.55^{\circ} \mathrm{S}\right)$, southern Chile", and a contribution of the Wankara Laboratory.

\section{References}

1. Anderson CB, Rozzi R, Torres-Mura JC, Mcgehee SM, Sherriffs MF, Schüttler E, Rosemond AD (2006) Exotic vertebrate fauna in the remote and pristine sub-Antarctic Cape Horn Archipelago, Chile. 
Biodivers. Conserv. 15(10):3295-3313. https://doi.org/10.1007/s10531-005-0605-y

2. Anderson MJ (2005) PERMANOVA: a FORTRAN computer program for permutational multivariate analysis of variance. Department of Statistics, University of Auckland, New Zealand.

3. Barnes BM, Barger JL, Seares J, Tacquard PC, Zuercher GL (1996) Overwintering in yellowjacket queens (Vespula vulgaris) and green stinkbugs (Elasmostethus interstinctus) in subarctic Alaska. Physiol. Zool. 69(6):1469-1480. https://doi.org/10.1086/physzool.69.6.30164270

4. Barrera-Medina R, Vidal C (2013) Primer reporte de Vespula vulgaris (Linnaeus, 1758) (Hymenoptera: Vespidae) en Chile. Boletín de la S.E.A. 52:277-278.

5. Beggs JR (2001) The ecological consequences of social wasps (Vespula spp.) invading an ecosystem that has an abundant carbohydrate resource. Biol. Conserv. 99(1):17-28. https://doi.org/10.1016/S0006-3207(00)00185-3

6. Beggs JR, Brockerhoff EG, Corley JC, Kenis M, Masciocchi M, Muller F, Rome Q, \& Villemant C (2011) Ecological effects and management of invasive alien Vespidae. BioControl 56(4):505-526. https://doi.org/10.1007/s10526-011-9389-z

7. Beggs JR, Rees JS (1999) Restructuring of Lepidoptera communities by introduced Vespula wasps in a New Zealand beech forest. Oecologia 119(4):565-571. https://doi.org/10.1007/s004420050820

8. Beggs JR, Toft RJ, Malham JP, Rees JS, Tilley JAV, Moller H, Alspach P (1998) The difficulty of reducing introduced wasp (Vespula vulgaris) populations for conservation gains. N. Z. J. Ecol. 55-63.

9. Bertolino S, Lioy S, Laurino D, Manino A, Porporato M (2016) Spread of the invasive yellow-legged hornet Vespa velutina (Hymenoptera:Vespidae) in Italy. Appl. Entomol. Zool. 51(4):589-597. https://doi.org/10.1007/s13355-016-0435-2

10. Blackburn TM, Pyšek P, Bacher S, Carlton JT, Duncan RP, Jarošík V, Wilson JRU, Richardson DM (2011) A proposed unified framework for biological invasions. Trends Ecol. Evol. 26(7):333-339. https://doi.org/10.1016/j.tree.2011.03.023

11. Brenton-Rule EC, Dobelmann J, Baty JW, Brown RL, Dvorak L, Grangier J, Masciocchi M, McGrannachan C, Shortall CR, Schmack J, van Zyl C, Veldtman R, Lester PJ (2018) The origins of global invasions of the German wasp (Vespula germanica) and its infection with four honey bee viruses. Biol. Invasions 20(12):3445-3460. https://doi.org/10.1007/s10530-018-1786-0

12. Clarke KR, Gorley RN (2015) Getting started with PRIMER v7. PRIMER-E: Plymouth, Plymouth Marine Laboratory.

13. Convey P (1996) Overwintering strategies of terrestrial invertebrates from Antarctica - the significance of flexibility in extremely seasonal environments. Eur. J. Entomol. 93:489-505.

14. Crête G, Herrmann TM, Fortin C, Schüttler E (2020) Public perceptions of non-native plant species on a Chilean sub-Antarctic island. Polar Geogr. 43(1):46-63.

https://doi.org/10.1080/1088937X.2019.1707321

15. Danks HV (1996) The wider integration of studies on insect cold-hardiness. Eur. J. Entomol. 93:383404. 
16. Gardner-Gee R, Beggs JR (2013) Invasive wasps, not birds, dominate in a temperate honeydew system. Austral Ecol. 38(3):346-354. https://doi.org/10.1111/j.1442-9993.2012.02412.x

17. Garnas JR, Auger-Rozenberg MA, Roques A et al (2016) Complex patterns of global spread in invasive insects: eco-evolutionary and management consequences. Biol. Invasions 18(4):935-952. https://doi.org/10.1007/s10530-016-1082-9

18. Grangier J, Lester PJ (2011) A novel interference behaviour: invasive wasps remove ants from resources and drop them from a height. Biol. Lett. 7(5):664-667.

https://doi.org/10.1098/rsbl.2011.0165

19. Harris RJ (1991) Diet of the wasps Vespula vulgaris and V. germanica in honeydew beech forest of the South Island, New Zealand. N. Z. J. Zool. 18(2):159-169.

https://doi.org/10.1080/03014223.1991.10757963

20. Hughes KA, Convey $P$ (2012) Determining the native/non-native status of newly discovered terrestrial and freshwater species in Antarctica-current knowledge, methodology and management action. J. Environ. Manage. 93(1):52-66. https://doi.org/10.1016/j.jenvman.2011.08.017

21. Hulme PE (2009) Trade, transport and trouble: managing invasive species pathways in an era of globalization. J. Appl. Ecol. 46:10-18. https://doi.org/10.1111/j.1365-2664.2008.01600.x

22. Kasper ML, Reeson AF, Austin AD (2008) Colony characteristics of Vespula germanica (F.) (Hymenoptera, Vespidae) in a Mediterranean climate (southern Australia). Aust. J. Entomol. 47(4):265-274. https://doi.org/10.1111/j.1440-6055.2008.00658.x

23. Lebouvier M, Lambret P, Garnier A, Convey P, Frenot Y, Vernon P, Renault D (2020) Spotlight on the invasion of a carabid beetle on an oceanic island over a 105-year period. Sci. Rep. 10(1):1-17. https://doi.org/10.1038/s41598-020-72754-5

24. Lester PJ, Beggs JR (2019) Invasion success and management strategies for social Vespula wasps. Annu. Rev. Entomol. 64:51-71. https://doi.org/10.1146/annurev-ento-011118-111812

25. Lester PJ, Haywood J, Archer ME, Shortall CR (2017) The long-term population dynamics of common wasps in their native and invaded range. J. Anim. Ecol. 86(2):337-347. https://doi.org/10.1111/13652656.12622

26. MacLeod CJ, Newson SE, Blackwell G, Duncan RP (2009) Enhanced niche opportunities: can they explain the success of New Zealand's introduced bird species?. Divers. Distrib. 15(1):41-49. https://doi.org/10.1111/j.1472-4642.2008.00498.x

27. Malham JP, Rees JS, Alspach PA, Beggs JR, Moller H (1991) Traffic rate as an index of colony size in Vespula wasps. N. Z. J. Zool. 18(2):105-109. https://doi.org/10.1080/03014223.1991.10757956

28. Masciocchi M, Beggs JR, Carpenter JM, Corley JC (2010) Primer registro de Vespula vulgaris (Hymenoptera: Vespidae) en la Argentina. Rev. Soc. Entomol. Arg. 69:267-270.

29. Masciocchi M, Corley J (2013) Distribution, dispersal and spread of the invasive social wasp (Vespula germanica) in Argentina. Austral Ecol. 38(2):162-68. https://doi.org/10.1111/j.14429993.2012.02388.x 
30. Mittermeier RA, Mittermeier CG, Brooks TM, Pilgrim JD, Konstant WR, Da Fonseca GA, Kormos C (2003) Wilderness and biodiversity conservation. Proc. Natl Acad. Sci. U.S.A. 100(18):10309-10313. https://doi.org/10.1073/pnas.1732458100

31. Moller H (1996) Lessons for invasion theory from social insects. Biol. Conserv. 78:125-142. https://doi.org/10.1016/0006-3207(96)00022-5

32. Parmesan C, Ryrholm N, Stefanescu C et al (1999) Poleward shifts in geographical ranges of butterfly species associated with regional warming. Nature 399(6736):579-583. https://doi.org/10.1038/21181

33. Peña L, Pérez de Arce R, Cartagena L (1975) La presencia de Vespula maculifrons (Buysson) (Hymenoptera: Vespidae) en Chile. Revista Chilena de Entomología 9:167-168.

34. Pereira AJ, Pirk GI, Corley JC (2016) Foraging behavior interactions between two non-native social wasps, Vespula germanica and $V$. vulgaris (Hymenoptera: Vespidae): implications for invasion success?. J. Insect Sci. 16(1). https://doi.org/10.1093/jisesa/iew058

35. Pérez V (2000) La avispa" chaqueta amarilla", Vespula germanica (Fabricius) (Hymenoptera: Vespidae), en la región de Magallanes. Ans. Ins. Patagon. 28:139-142.

36. Pisano E (1977) Fitogeografía de Revista Chilena de Entomología Fuego-Patagonia Chilena 1. Comunidades vegetales entre las latitudes 52-56 S. Ans. Ins. Patagon. 8:121-250.

37. Pyšek P, Hulme PE, Simberloff D et al (2020) Scientists' warning on invasive alien species. Biol. Rev. 95(6):1511-1534. https://doi.org/10.1111/brv.12627

38. Rendoll-Cárcamo J, Contador T, Crego RD et al (2016) Primer registro de Vespula vulgaris (Linnaeus 1758) (Hymenoptera: Vespidae) en la isla Navarino, Chile. Gayana 80:133-136. http://dx.doi.org/10.4067/S0717-65382016000100014

39. Rendoll-Cárcamo J, Contador T, Menares Zúñiga L (2017a) Observaciones sobre robo primario de néctar de Vespula vulgaris L., 1758 (Hymenoptera: Vespidae) en flores de Embothrium coccineum (JR Forst. \& G. Forst., 1775) (Proteaceae) en el sur de chile (55 S). Ans. Ins. Patagon. 45(3):73-78. http://dx.doi.org/10.4067/S0718-686X2017000300073

40. Rendoll-Carcamo J, Contador TA, Saavedra L, Montalva J (2017b) First record of the invasive bumblebee Bombus terrestris (Hymenoptera: Apidae) on Navarino Island, southern Chile ( $\left.55^{\circ} \mathrm{S}\right) . \mathrm{J}$. Melittology (71):1-5. https://doi.org/10.17161/jom.v0i71.6520

41. Richter MR (2000) Social wasp (Hymenoptera: Vespidae) foraging behavior. Annu. Rev. Entomol. 45(1):121-150. https://doi.org/10.1146/annurev.ento.45.1.121

42. Rosenfeld S, Convey P, Contador T et al (2020) Magallanes, laboratorio del cambio global. In: Rozzi R, Morello F, Massardo F. Aldunate C (eds.) Estrecho de Magallanes: Tres Descubrimientos. Santiago, Chile: Colección Santander, Museo de Chileno de Arte Precolombino, pp. 176-193.

43. Roy HE, Bacher S, Essl F, Adriaens T et al (2019). Developing a list of invasive alien species likely to threaten biodiversity and ecosystems in the European Union. Glob. Change Biol. 25(3):1032-1048. https://doi.org/10.1111/gcb.14527 
44. Rozzi, R, Crego RD, Contador T et al (2020) Un centinela para el monitoreo del cambio climático y su impacto sobre la biodiversidad en la cumbre austral de América: la nueva red de estudios a largo Plazo Cabo de Hornos. Ans. Ins. Patagon. 48(3):45-81. http://dx.doi.org/10.4067/S0718686X2020000300045

45. Rozzi R, Armesto JJ, Gutiérrez J et al (2012) Integrating ecology and environmental ethics: Earth stewardship in the southern end of the Americas. BioScience 62(3):226-236. https://doi.org/10.1525/bio.2012.62.3.4

46. Rust MK, Su NY (2012) Managing social insects of urban importance. Annu. Rev. Entomol. 57:355375. https://doi.org/10.1146/annurev-ento-120710-100634

47. Sackmann P, Corley JC (2007) Control of Vespula germanica (Hym. Vespidae) populations using toxic baits: bait attractiveness and pesticide efficacy. J. Appl. Entomol. 131(9-10):630-36. https://doi.org/10.1111/j.1439-0418.2007.01132.x

48. Sola FJ, Valenzuela AEJ, Anderson CB, Martínez Pastur G, Lencinas MV (2015) Reciente invasión del Archipiélago de Tierra del Fuego por la avispa Vespula germanica (Hymenoptera: Vespidae). Rev. Soc. Entomol. Arg. 74(3-4):197-202.

49. Sorvari J (2013) Social wasp (Hymenoptera: Vespidae) beer trapping in Finland 2008-2012: a German surprise. Entomol. Fenn. 24(3):156-164. https://doi.org/10.33338/ef.8983

50. Toft RJ, Rees JS (1998) Reducing predation of orb-web spiders by controlling common wasps (Vespula vulgaris) in a New Zealand beech forest. Ecol. Entomol. 23(1):90-95. https://doi.org/10.1046/j.1365-2311.1998.00100.x

51. Vanbergen AJ, Espíndola A, Aizen MA (2018) Risks to pollinators and pollination from invasive alien species. Nat. Ecol. Evol. 2:16-25. https://doi.org/10.1038/s41559-017-0412-3

\section{Figures}




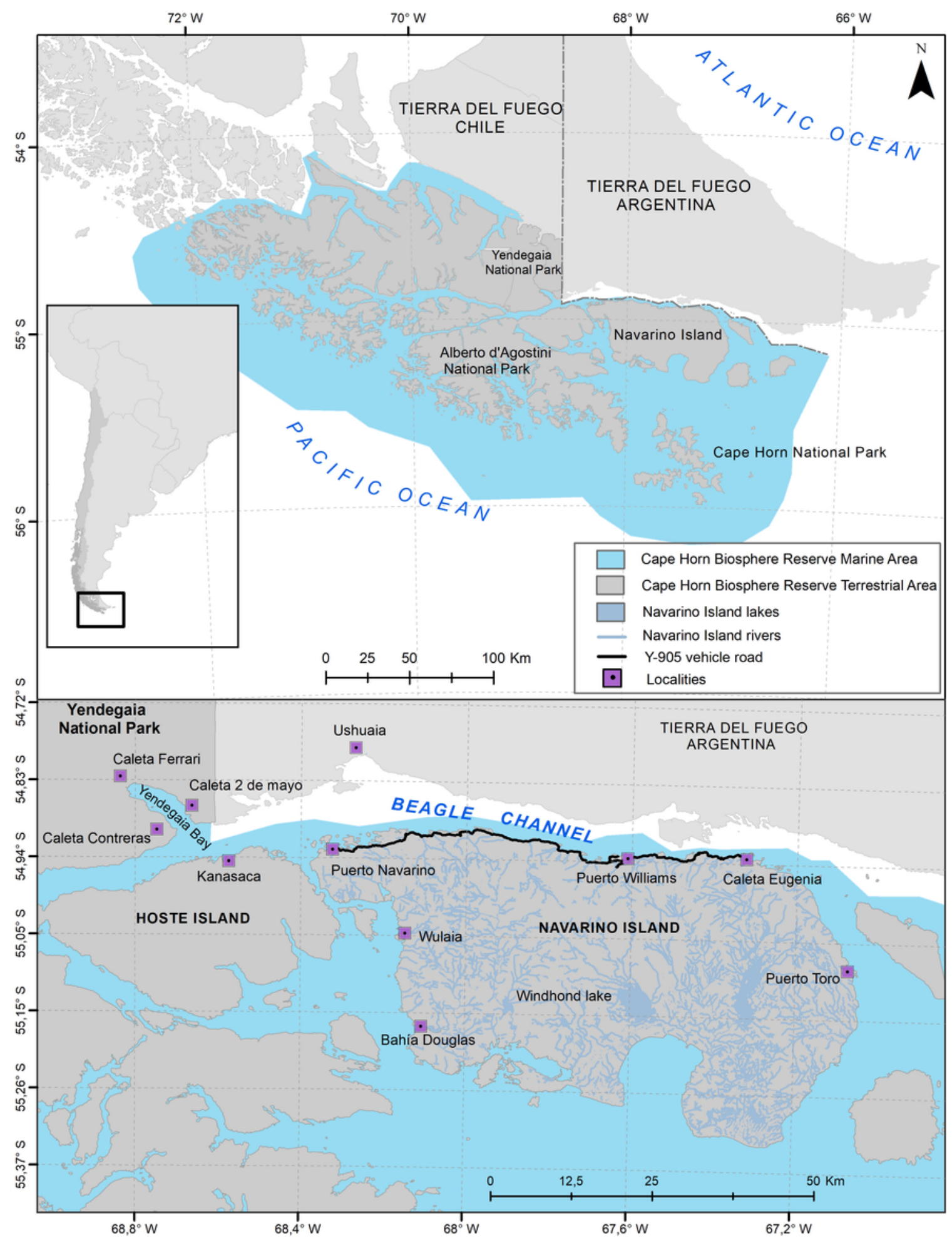

\section{Figure 1}

Cape Horn Biosphere Reserve location in southern South America. Purple squares indicate localities mentioned in the text. The vehicular road on Navarino Island $(\mathrm{Y}-905)$ is shown in the north coast of the island (black line) 


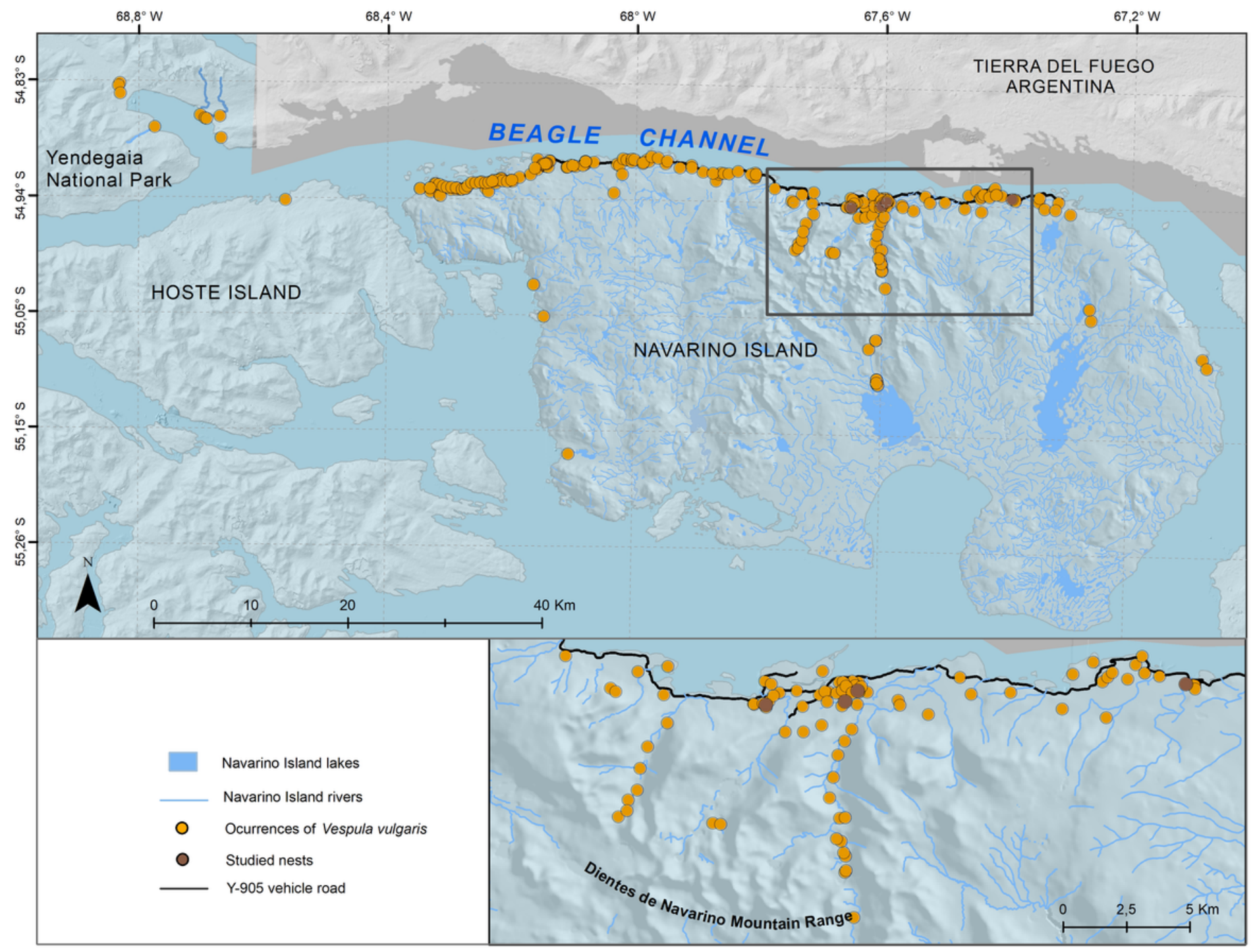

Figure 2

Vespula vulgaris distribution records ( $\mathrm{n}=224$, yellow circles) and studied nests (green circles and zoomed) in the southern area of the Cape Horn Biosphere Reserve 


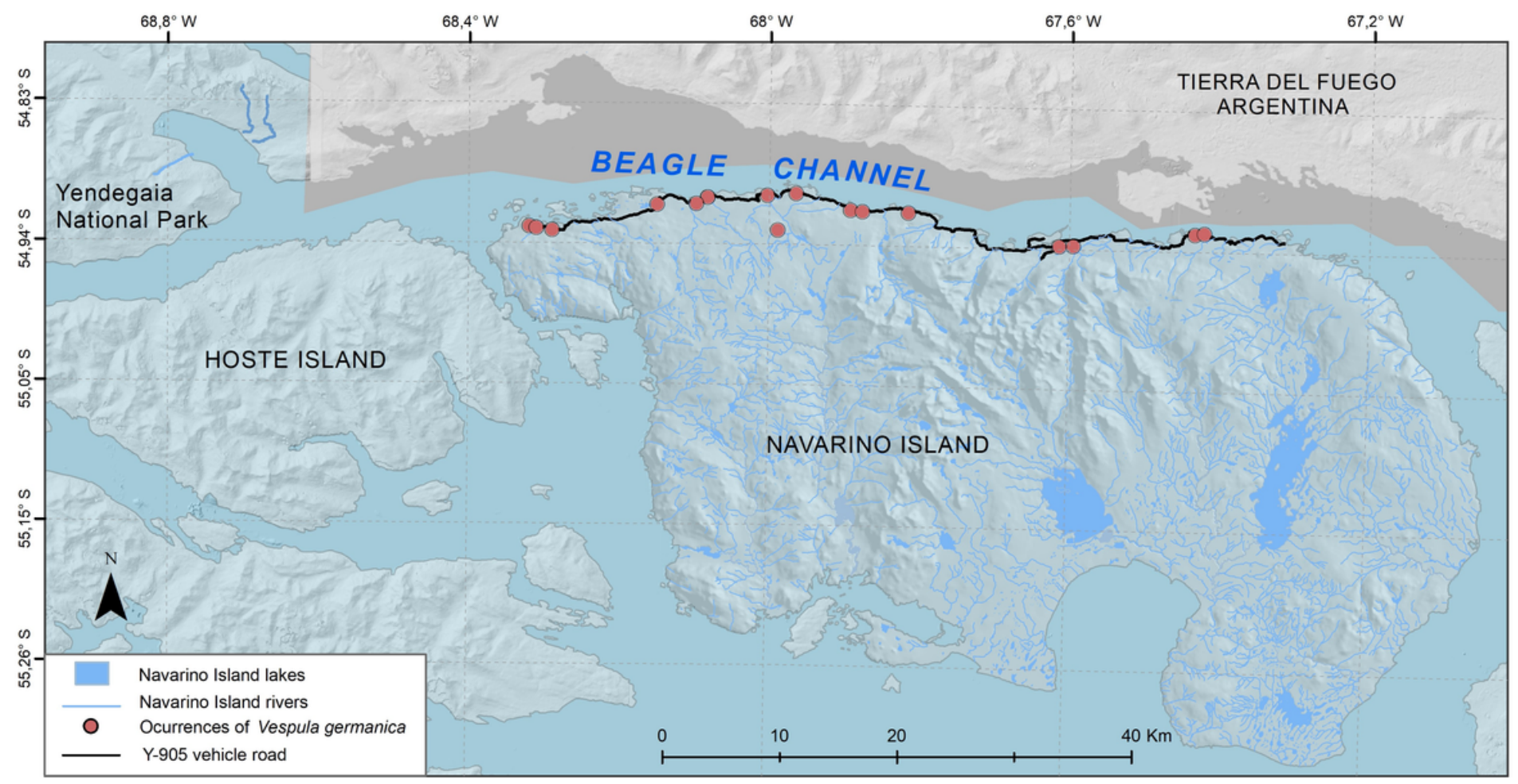

\section{Figure 3}

Vespula germanica distribution records ( $\mathrm{n}=32$, colored circles) colored circles) in the Cape Horn Biosphere Reserve 


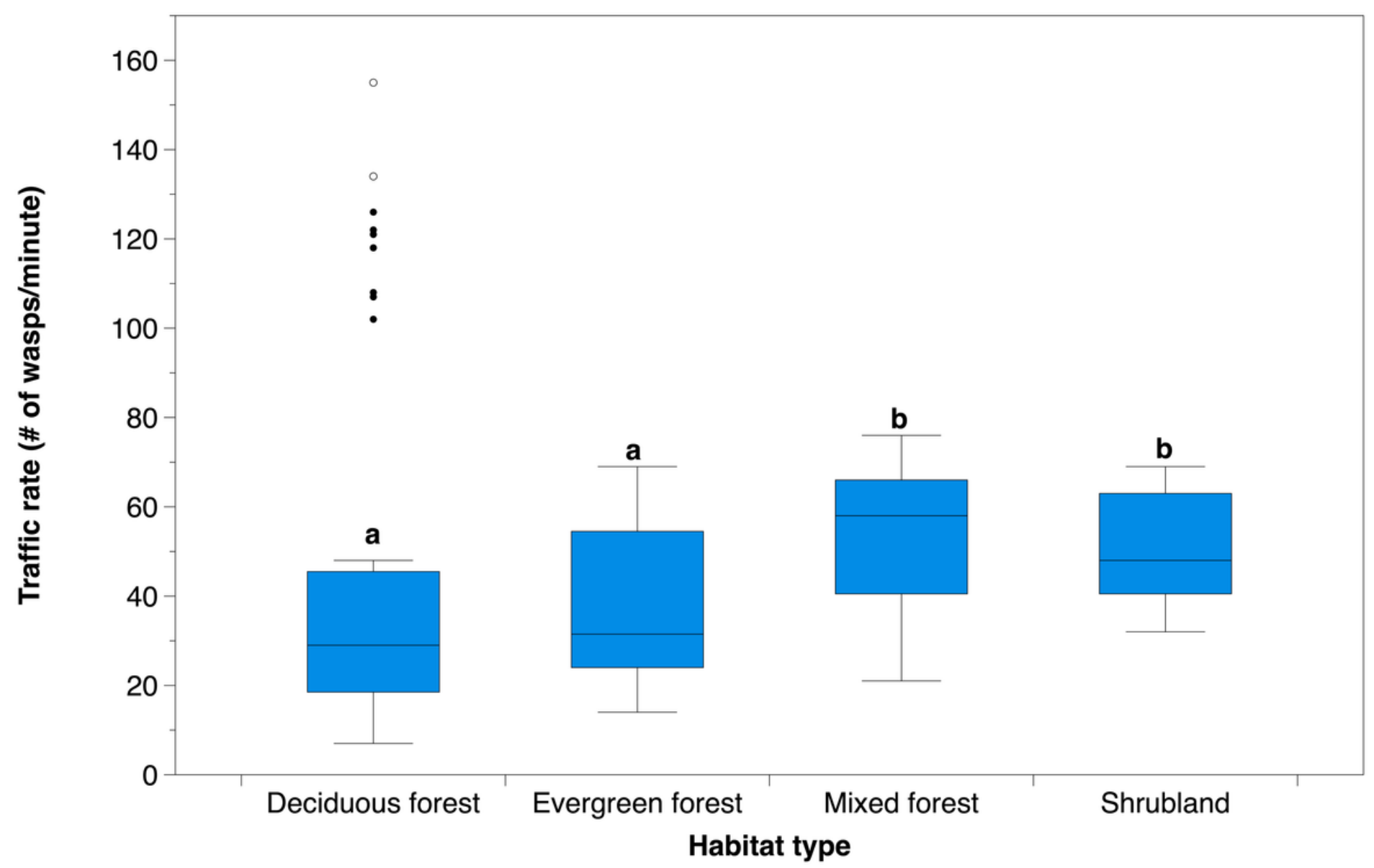

\section{Figure 4}

Boxplot of mean traffic rates observed at the entrance of Vespula vulgaris nests per habitat. The 25th and 75th percentiles are shown (lower and upper box boundaries), along with median (line inside box) and 10th and 90th percentiles (lower and upper error lines); different letters denote statistically significant differences 


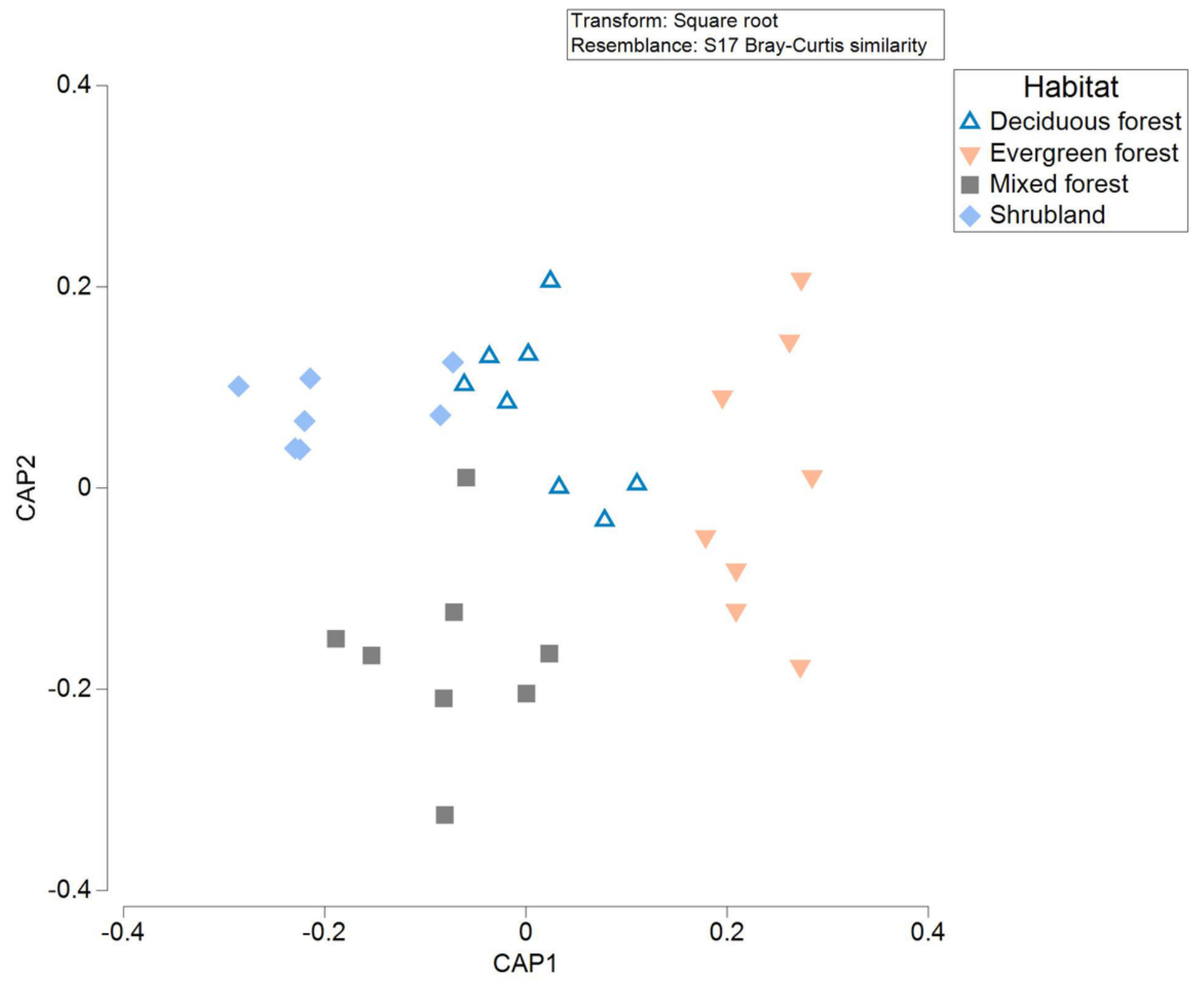

\section{Figure 5}

Canonical Analysis of Principal coordinates (CAP) of foraged item composition by Vespula vulgaris on each studied habitat (figures and colors), based on a Bray-Curtis similarity matrix with data square root transformed 

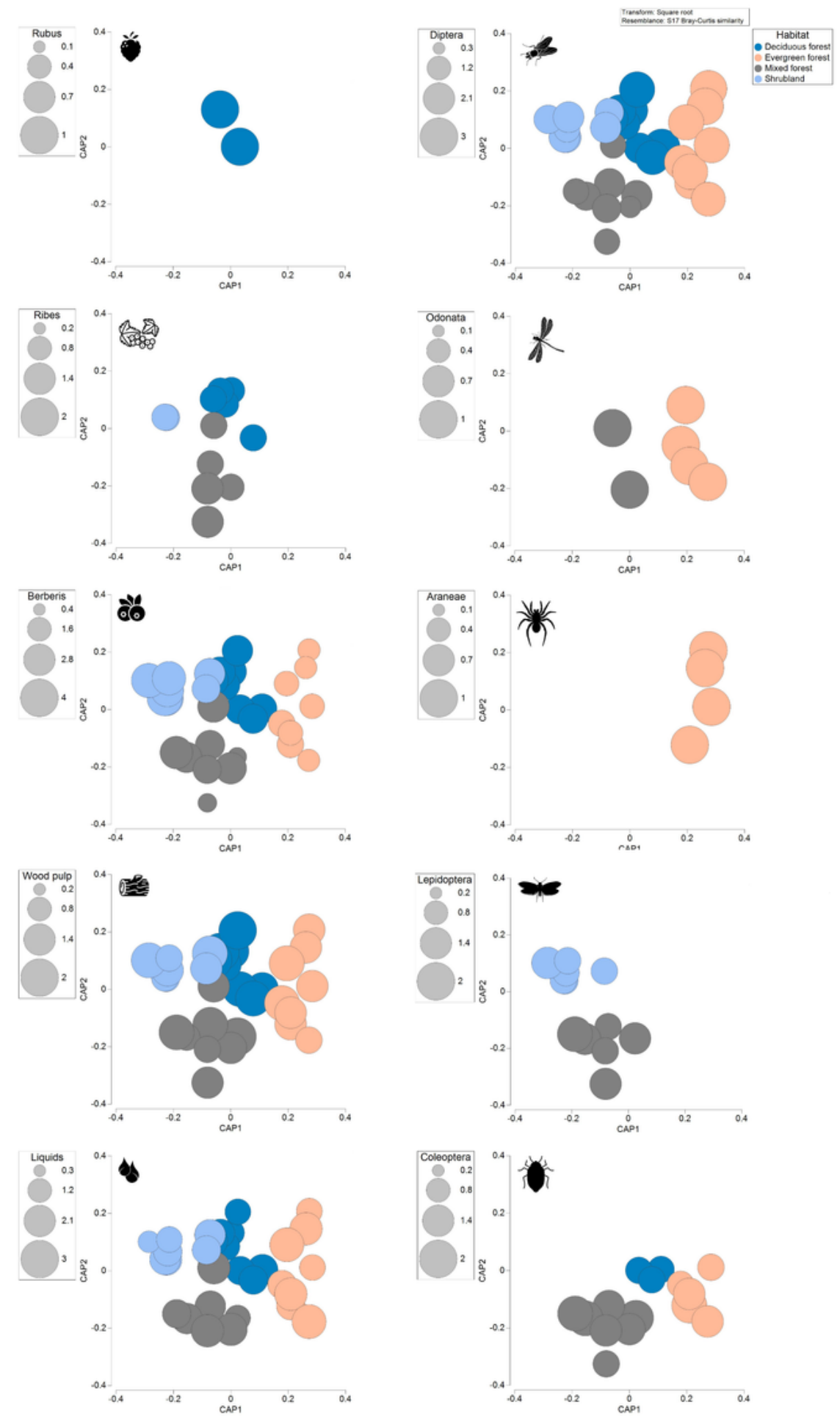

\section{Figure 6}

Canonical Analysis of Principal coordinates (CAP) of each foraged item by Vespula vulgaris on each studied habitat (colors) and their abundance (circle size), based on a Bray-Curtis similarity matrix with data square root transformed 
A)

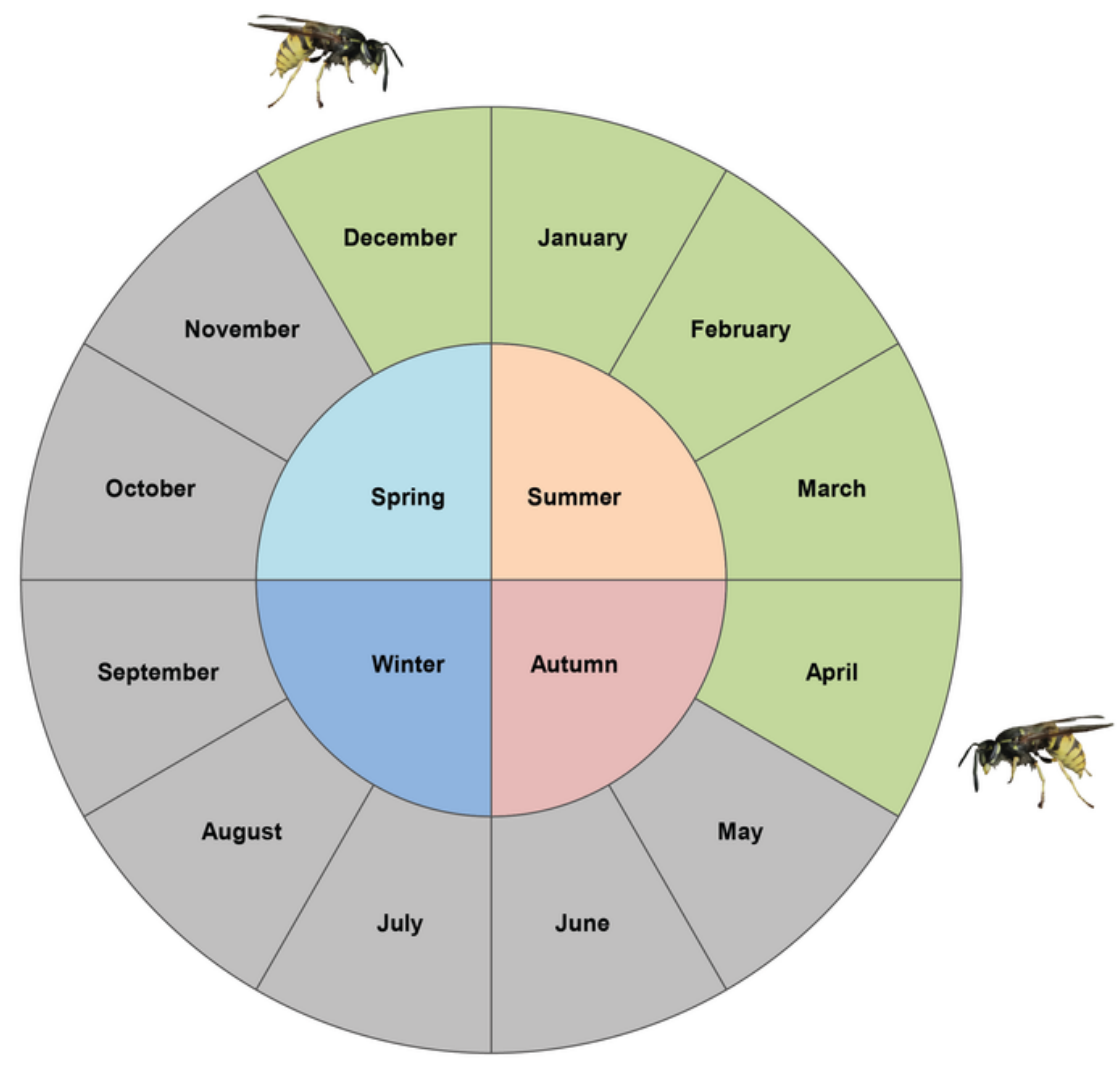

B)

C)

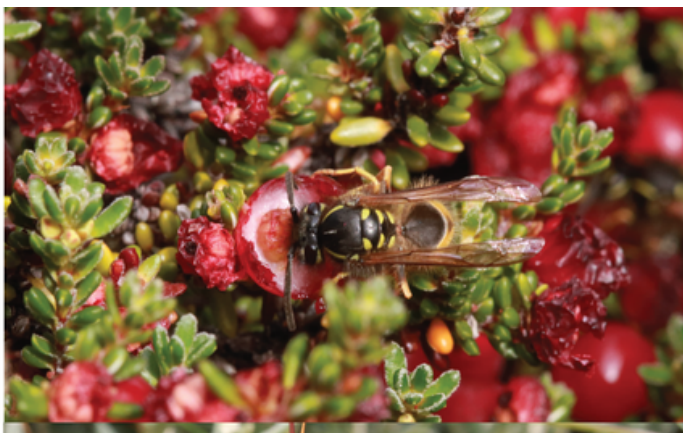

D)
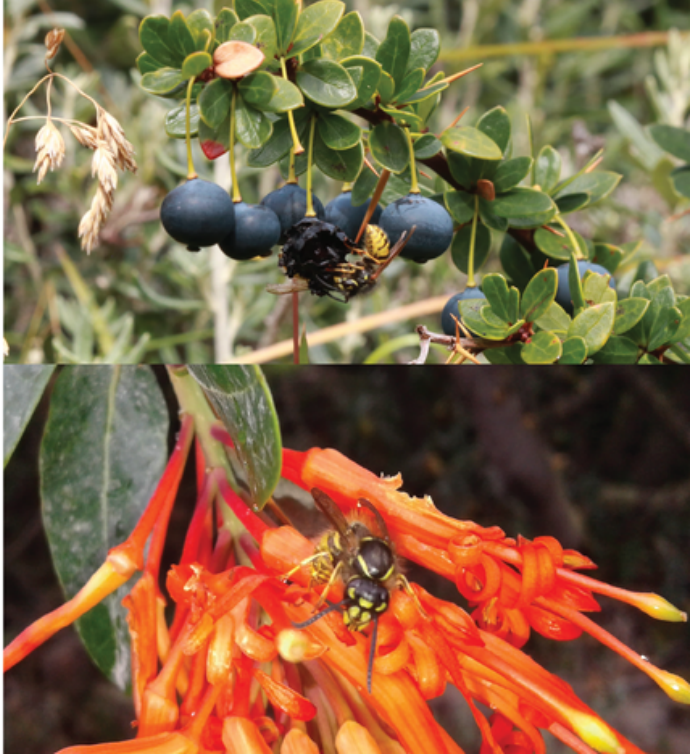

\section{Figure 7}

Conceptual cycle of Vespula vulgaris (A) population dynamics through the year and interactions with native biota (B, C and D) in the Cape Horn Biosphere Reserve, southern Chile. A) Wasp activity starts late in spring with the emergence of fertilized queens from hibernation and the production of the first cohort of workers, through the summer workers start foraging and expanding the nest, and in early autumn starts the new queen and drone production, mating and the search for hibernation shelters. B, C and D), Wasps foraging Empetrum rubrum and Berberis microphylla berries, and robbing nectar from Embothrium coccineum flowers 